\begin{tabular}{|c|c|}
\hline Title & Parentage assignment in hatchery population of brown sole Pleuronectes herzensteini by microsatellite DNA markers \\
\hline Author(s) & Kim, Sang-Gyu; Morishima, Kagayaki; Satoh, Nobukazu; Fujioka, Takashi; Saito, Setsuo; A rai, Katsutoshi \\
\hline Citation & $\begin{array}{l}\text { Fisheries Science, 73(5), 1087-1093 } \\
\text { https://doi.org/10.1111 j.1444 2906.2007.01440.x }\end{array}$ \\
\hline Issue Date & $2007-10$ \\
\hline Doc URL & http:/hdl .handle.net/2115/35582 \\
\hline Rights & ○ 2007 公益社団法人日本水産学会; @ 2007 The Japanese Society of Fisheries Science \\
\hline Type & article \\
\hline File Information & 2007-73_p1087-1093.pdf \\
\hline
\end{tabular}

Instructions for use 


\title{
Parentage assignment in hatchery population of brown sole Pleuronectes herzensteini by microsatellite DNA markers
}

\author{
Sang-Gyu KIM, ${ }^{\text {la }}$ Kagayaki MORISHima, ${ }^{\text {lb }}$ Nobukazu SATOH, ${ }^{2 \mathrm{c}}$ Takashi FUJIOKA, ${ }^{2 \mathrm{~d}}$ Setsuo \\ SAITO $^{2 \mathrm{C}}$ AND KATSUTOSHI ARAI ${ }^{1 *}$ \\ ${ }^{1}$ Graduate School of Fisheries Sciences, Hokkaido University, Hakodate, Hokkaido 041-8611, and \\ ${ }^{2}$ Hokkaido Institute of Mariculture, Shikabe, Hokkaido 041-1404, Japan
}

\begin{abstract}
Five loci (Phz2, Phz6, Phz7, Phz12, and Phz14) of microsatellite DNA markers developed in a previous study for parentage assignment in the hatchery population generated by mating among 61 broodstock fish ( 35 females and 26 males) in a spawning tank, were selected. After natural spawning in the same tank, larvae collected at three different times were categorized into early phase (EP), middle phase (MP), and late phase (LP) groups. In the parental broodstock, the mean number of alleles per locus was 21.8 and expected heterozygosity $\left(H_{E}\right)$ was 0.813 . In the progeny, the mean number of alleles per locus decreased to 11.6 (EP), 14.4 (MP), and 6.4 (LP) and $H_{E}$ to 0.796 (EP), 0.833 (MP), and 0.681 (LP). Parental assignment determined eight dams and six sires as major parents for the EP group. In the MP group, 13 dams and ten sires genetically contributed to spawning, but only three dams and two sires were involved in LP group progeny. In the hatchery population produced from a limited number of parental fish such as the LP group, genetic variability was apparently decreased.
\end{abstract}

KEY WORDS: effective population size, genetic diversity, hatchery population, heterozygosity, microsatellite DNA, parentage assignment, Pleuronectes herzensteini.

\section{INTRODUCTION}

Microsatellites consist of multiple copies of tandem repeats of di-, tri-, and tetranucleotide sequences and are distributed throughout the regions of the genome. ${ }^{1}$ Microsatellites are ideal molecular markers for various genetic studies because they are highly polymorphic, codominant in the manner of inheritance, and easy to genotype by polymerase chain reaction (PCR). ${ }^{2}$ Thus, these markers have been used extensively in various aspects of aquatic organisms including gene

*Corresponding author: Tel: 81-138-40-5535.

Fax: 81-138-40-5537. Email: araikt@fish.hokudai.ac.jp

apresent address: Korea Inter-University Institute of Ocean Science, Pukyong National University, 599-1, Daeyeun, Namgu, Busan 608-737, Korea.

'Present address: Fisheries Laboratory, Kinki University, Shirahama, Wakayama 649-2211, Japan.

'Present address: Hokkaido Mariculture Fisheries Experiment Station, Muroran, Hokkaido 051-0013, Japan.

${ }^{d}$ Present address: Hokkaido Hakodate Fisheries Experiment Station, Hakodate, Hokkaido 042-0932, Japan.

Received 22 November 2006. Accepted 14 May 2007. mapping, allocation of parentage, kinships, and stock structure in the field of fisheries science. ${ }^{3}$ Recently, microsatellite DNA markers have also been actively developed and widely used for genetic studies of natural populations, ${ }^{4-6}$ parentage assignment, ${ }^{7-12}$ and the management of resources of various kinds of commercially important aquatic animals. ${ }^{13-18}$

Brown sole Pleuronectes herzensteini is an important species as an inshore fishery resource in Japan. Recently, stock enhancement by release has been expanded, because optimal conditions for rearing and feeding brown sole larvae have been clarified, and artificial production of seedlings has been technically established by the Hokkaido Mariculture Fisheries Experiment Station (formerly Hokkaido Institute of Mariculture), Japan. ${ }^{19,20}$ In the resource rehabilitation project, the genetic impact of artifcial release of the hatchery population should be considered from the viewpoint of conservation of the genetic diversity of the wild population. In the artificial production of seedlings, the available number of parent fish is generally limited as a result of space in the hatchery and unconscious selection 
may decrease genetic variability, because seed production procedures are normally designed for the convenience of hatchery workers and the efficient use of spawning and rearing facilities in the hatchery. Thus, release of the hatchery population is being reconsidered so as not to damage the genetic integrity of the natural population. The understanding of genetic variation through parentage assignment is an important step for the management and conservation of fishery resources.

In the present study, genetic variability was compared between hatchery populations from different spawning times and parental broodstock using microsatellite DNA markers previously developed. ${ }^{21}$ Each progeny population was also investigated for genetic variability. Parentage assignment was then examined between parental broodstock and hatchery progeny.

\section{MATERIALS AND METHODS}

\section{Flatfish samples}

Parental fish of brown sole Pleuronectes herzensteini broodstock were caught by trawling in the coastal area of Erimo district, Hokkaido, Japan in 2003. They were transported alive and then reared as broodstock at the Hokkaido Institute of Mariculture, Shikabe, Hokkaido, Japan. Progeny were produced by natural spawning using 61 parental fish (35 females, 26 males) in an 8-t round fiberreinforced plastic tank. To examine the number of parental fish that contribute to production of progeny in different phases during the spawning period, fertilized eggs collected on 18 May, 25 May, and 6 July 2004 were designated as early phase (EP), middle phase (MP), and late phase (LP) groups, respectively, and reared separately. Approximate numbers of fertilized eggs were 864000 in EP, 1150000 in MP, and 60800 in LP. Approximately 25000 hatched fry from each group were moved to an independent rearing tank. The survival rate of 3 -month-old progeny was $29.5 \%$ in EP, $44.0 \%$ in MP, and $10.1 \%$ in LP. Sixty-four progeny per phase were randomly collected for microsatellite DNA genotyping.

\section{Parentage assignment and data analysis}

Genomic DNA was extracted from fin clips of parents, and whole 3-month-old progeny belonging to each of the spawning groups (EP, MP, and LP). PCR was performed in $10 \mu \mathrm{L}$ reaction volumes containing a 50-100 ng DNA template. The reaction mixture contained $0.05 \mu \mathrm{L}(5 \mathrm{U} / \mu \mathrm{L}) \quad r$ Taq polymerase (TaKaRa, Shiga, Japan), $1 \mu \mathrm{L} 10 \times \mathrm{PCR}$ buffer, $0.8 \mu \mathrm{L}$ dNTPs $(200 \mu \mathrm{M}), 0.33 \mu \mathrm{L}(1 \mathrm{pmol} /)$ M13 tailed forward primer, $0.33 \mu \mathrm{L}(10 \mathrm{pmol} / \mu \mathrm{L})$ reverse primer, and $0.33 \mu \mathrm{L}(10 \mathrm{pmol} / \mu \mathrm{L})$ labeled M13M1 primer (5'-CACGACGTTGTAAAACGAC$\left.3^{\prime}\right) .^{22,23}$ The labeled M13 primer was labeled at the $5^{\prime}$ end with VIC, NED or PET fluorescent dyes (Applied Biosystems, Foster City, CA, USA). The PCR condition was 32 cycles of denaturing for $15 \mathrm{~s}$ at $94^{\circ} \mathrm{C}$, annealing for $15 \mathrm{~s}$ at $56^{\circ} \mathrm{C}$ and extension for $30 \mathrm{~s}$ at $72^{\circ} \mathrm{C}$, and final extension for $30-60 \mathrm{~min}$ at $72^{\circ} \mathrm{C}$. Genotypes were determined as approximate allele sizes (base pairs) by a 3130xl Prism genetic analyzer (Applied Biosystems) and GENEMAPPER software v.3.7 (Applied Biosystems) using comLIZ 500 as the size standard. Five microsatellite loci (Phz2, Phz6, Phz7, Phz12, and Phz14) were amplified using primers developed by Kim et al. ${ }^{21}$

Parentage allocation using genotypes was performed using PAPA v2.0 software ${ }^{24}$ based on breeding likelihood. ${ }^{25}$ For the purpose of characterizing variation at the five microsatellite loci, data from the parent and progeny samples were analyzed. Allele frequencies and expected heterozygosity $\left(H_{E}\right)$ in parents and progeny groups were calculated for each locus. The observed heterozygosity $\left(H_{0}\right)$ was calculated directly from observed genotypes. These statistical analyses were conducted using GENEPOP v3.4. ${ }^{26}$

The effective number of parents contributing to the progeny was estimated by effective population size $\left(N_{e}\right)$ in each phase according to Lande and Barrowclough: ${ }^{27}$

$$
\begin{gathered}
N_{e}=4 N_{e f} N_{e m} /\left(N_{e f}+N_{e m}\right) \\
N_{e f}=\left(N_{f} \bar{K}_{f}-1\right) /\left[\bar{K}_{f}-1+\left(\delta^{2}{ }_{K f} / \bar{K}_{f}\right)\right],
\end{gathered}
$$

where $N_{e f}$ and $N_{e m}$ are the effective number of breeding females and males, respectively, $N_{f}$ is the census number of females, $\bar{K}_{f}$ is the average number of progeny dammed by each female, and $\delta^{2}{ }_{K f}$ is the variance in female progeny number. The same formula was used to calculate the effective number of breeding males, $N_{e m}$.

\section{RESULTS}

\section{Parentage assignment}

Parentage assignment was successfully determined in $92.2 \%$ (59/64), $84.4 \%(54 / 64)$, and $100 \%(64 / 64)$ progeny of the EP, MP, and LP groups, respectively. Parentage assignment succeeded for $92.2 \%$ of all the progeny examined. Eight dams and six sires, 13 dams and ten sires, and three dams and two sires were identified as predominantly participating in 
Table 1 Dams and sires contributing to spawning in early, middle and late phases

\begin{tabular}{|c|c|c|c|c|c|c|c|c|c|}
\hline \multirow{2}{*}{$\begin{array}{l}\text { Dam } \\
\#\end{array}$} & \multicolumn{3}{|c|}{ Progeny } & \multirow[b]{2}{*}{ Total } & \multirow{2}{*}{$\begin{array}{c}\text { Sire } \\
\#\end{array}$} & \multicolumn{3}{|c|}{ Progeny } & \multirow[b]{2}{*}{ Total } \\
\hline & $\mathrm{EP}(\%)$ & MP(\%) & $\mathrm{LP}(\%)$ & & & $\mathrm{EP}(\%)$ & $\mathrm{MP}(\%)$ & LP(\%) & \\
\hline $2 \mathrm{~F}$ & 0 & $3(5.6)$ & 0 & $3(1.7)$ & $33 \mathrm{M}$ & $10(16.9)$ & $14(25.9)$ & 0 & $24(13.6)$ \\
\hline $7 \mathrm{~F}$ & $8(13.6)$ & $6(11.1)$ & 0 & $14(7.9)$ & $34 \mathrm{M}$ & 7 (11.9) & 0 & 0 & $7(4.0)$ \\
\hline $9 \mathrm{~F}$ & $5(8.5)$ & 0 & 0 & $5(2.8)$ & $35 \mathrm{M}$ & 18 (30.5) & 0 & 0 & $18(10.2)$ \\
\hline $11 \mathrm{~F}$ & $19(32.2)$ & $1(1.9)$ & 0 & $20(11.3)$ & $42 \mathrm{M}$ & 0 & 1 (1.9) & 0 & $1(0.6)$ \\
\hline $16 \mathrm{~F}$ & $6(10.2)$ & $1(1.9)$ & 0 & $7(4.0)$ & $45 \mathrm{M}$ & $8(13.6)$ & $5(9.3)$ & $47(73.4)$ & $60(33.9)$ \\
\hline $17 \mathrm{~F}$ & 0 & $2(3.7)$ & 0 & $2(1.1)$ & $47 \mathrm{M}$ & $7(11.9)$ & $10(18.5)$ & 0 & 17 (9.6) \\
\hline $18 \mathrm{~F}$ & $9(15.3)$ & $6(11.1)$ & 0 & $15(8.5)$ & $49 \mathrm{M}$ & 0 & 1 (1.9) & $17(26.6)$ & $18(10.2)$ \\
\hline $20 \mathrm{~F}$ & 0 & $1(1.9)$ & 0 & $1(0.6)$ & $50 \mathrm{M}$ & 0 & $8(14.8)$ & 0 & $8(4.5)$ \\
\hline $21 \mathrm{~F}$ & 0 & $14(25.9)$ & 0 & $14(7.9)$ & $51 \mathrm{M}$ & 0 & $4(7.4)$ & 0 & $4(2.3)$ \\
\hline $22 \mathrm{~F}$ & 0 & $5(9.3)$ & 0 & $5(2.8)$ & $54 \mathrm{M}$ & 0 & $3(5.6)$ & 0 & $3(1.7)$ \\
\hline $24 \mathrm{~F}$ & 0 & 0 & 20 (31.3) & 20 (11.3) & $57 \mathrm{M}$ & $9(15.3)$ & $6(11.1)$ & 0 & $15(8.5)$ \\
\hline $26 \mathrm{~F}$ & $6(10.2)$ & $2(3.7)$ & 0 & $8(4.5)$ & $58 \mathrm{M}$ & 0 & $2(3.7)$ & 0 & $2(1.1)$ \\
\hline $28 \mathrm{~F}$ & $4(6.8)$ & $8(14.8)$ & 0 & $12(6.8)$ & Total & 59 (100) & $54(100)$ & $64(100)$ & $177(100)$ \\
\hline $29 \mathrm{~F}$ & $2(3.4)$ & $4(7.4)$ & 0 & $6(3.4)$ & & & & & \\
\hline $30 F$ & 0 & $1(1.9)$ & 0 & $1(0.6)$ & & & & & \\
\hline $31 \mathrm{~F}$ & 0 & 0 & $27(42.2)$ & $27(15.3)$ & & & & & \\
\hline $61 \mathrm{~F}$ & 0 & 0 & 17 (26.6) & 17 (9.6) & & & & & \\
\hline Total & $59(100)$ & $54(100)$ & $64(100)$ & $177(100)$ & & & & & \\
\hline
\end{tabular}

EP, early phase; LP, last phase; MP, middle phase.

spawning in the EP, MP, and LP groups, respectively. As shown in Table 1 and Figure 1, 17 of 35 dams and 12 of 26 sires were determined to participate in the production of progeny.

In the EP group, only eight dams were determined to contribute to spawning and approximately $60 \%$ of larvae were the progeny of three dams (7F, 11F, and 18F, Table 1). Seven of eight dams contributing to EP produced approximately $50 \%$ of the MP, but they were not spawners in the LP group. In the LP group, most larvae were estimated as the progeny of only three dams $(24 \mathrm{~F}, 31 \mathrm{~F}$, and $61 \mathrm{~F}$ ). They did not contribute to spawning in EP and MP. Overall, $11 \mathrm{~F}, 24 \mathrm{~F}$, and $31 \mathrm{~F}$ predominantly participated in the production of the hatchery population and more than $37 \%$ of larvae were estimated to be their progeny. Six, ten, and two sires contributed to spawning in the EP, MP, and LP groups, respectively, but only one sire $(45 \mathrm{M})$ continued to mate during all three periods examined, and about $34 \%$ larvae were estimated as the progeny of the $45 \mathrm{M}$ sire (Table 1 ). In the MP group, ten sires contributed to spawning.

The number of dams and sires contributing to spawning in the MP group was larger than in the EP and LP groups (Fig. 1). These were nine, 15, and three parental pairs in EP, MP, and LP, respectively. In EP and LP, progeny were clustered around major parents; however, progeny appeared from a relatively large number of parental fishes participating in MP. Single pair mating was two $(7 \mathrm{~F} \times 45 \mathrm{M}$, $18 \mathrm{~F} \times 57 \mathrm{M})$ in $\mathrm{EP}$, four $(2 \mathrm{~F} \times 54 \mathrm{M}, 18 \mathrm{~F} \times 57 \mathrm{M}$,
$20 \mathrm{~F} \times 49 \mathrm{M}, \quad 28 \mathrm{~F} \times 50 \mathrm{M})$ in $\mathrm{MP}$, and only one $(61 \mathrm{~F} \times 49 \mathrm{M})$ in the LP group.

\section{Changes in genetic parameters}

In the parental broodstock, the number of alleles per locus varied from ten (Phz14 locus) to 38 (Phz12 locus), and the average $H_{E}$ was 0.834 (Table 2). In EP, MP, and LP progeny, the average $H_{E}$ was $0.796,0.833$, and 0.681 , respectively, and $N_{a}$ varied from six $(P h z 6)$ to 20 (Phz12), from six (Phz14) to 26 (Phz12), and from four (Phz6) to nine $(P h z 2)$. Especially in LP, $P h z 12$ showed reduction of $N_{a}$ to eight and Phz6 showed decreased $H_{E}=0.341$. These parameters were lower than estimated in the broodstock (parent) population (mean $N_{a}=21.8$, $H_{E}=0.834$ ), except for $H_{E}$ in MP. Thus, genetic variation of hatchery stock, especially in LP, was apparently reduced when compared with broodstock captured wild.

After identifying the pedigree, the effective population size $\left(N_{e}\right)$ was estimated as shown in Table 3. The effective number of females $\left(N_{\text {eff }}\right)$ was greater than that of males $\left(N_{\text {em }}\right)$ in each phase. Variance of contributions was higher in male parents $\left(\delta^{2}{ }_{\mathrm{Km}}\right)$ than in female parents $\left(\delta^{2}{ }_{\mathrm{Kf}}\right)$ in MP and LP. The $N_{E}$ was 11.25 in EP, 14.87 in MP, 3.78 in LP, and 15.3 in overall. The $N_{e} / N$ ratio was $0.18,0.24,0.06$, and 0.25 in EP, MP, LP and overall group, respectively, while the $N_{e} / N_{c}$ ratio was $0.80,0.65,0.76$, and 0.53 , respectively. 
(a)

35
\begin{tabular}{|l|l|l|l|l|}
\hline 03 & 06 & 07 & 10 & 14 \\
\hline 15 & 19 & 21 & 24 & 25 \\
\hline 41 & 42 & 43 & 48 & 53 \\
\hline & 59 & 62 & 64 & \\
\cline { 2 - 5 }
\end{tabular}

(11)

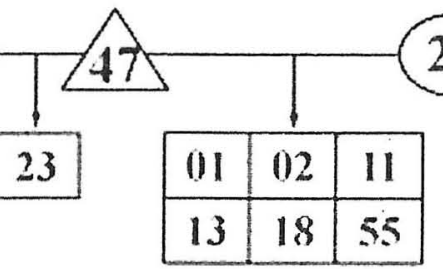

26
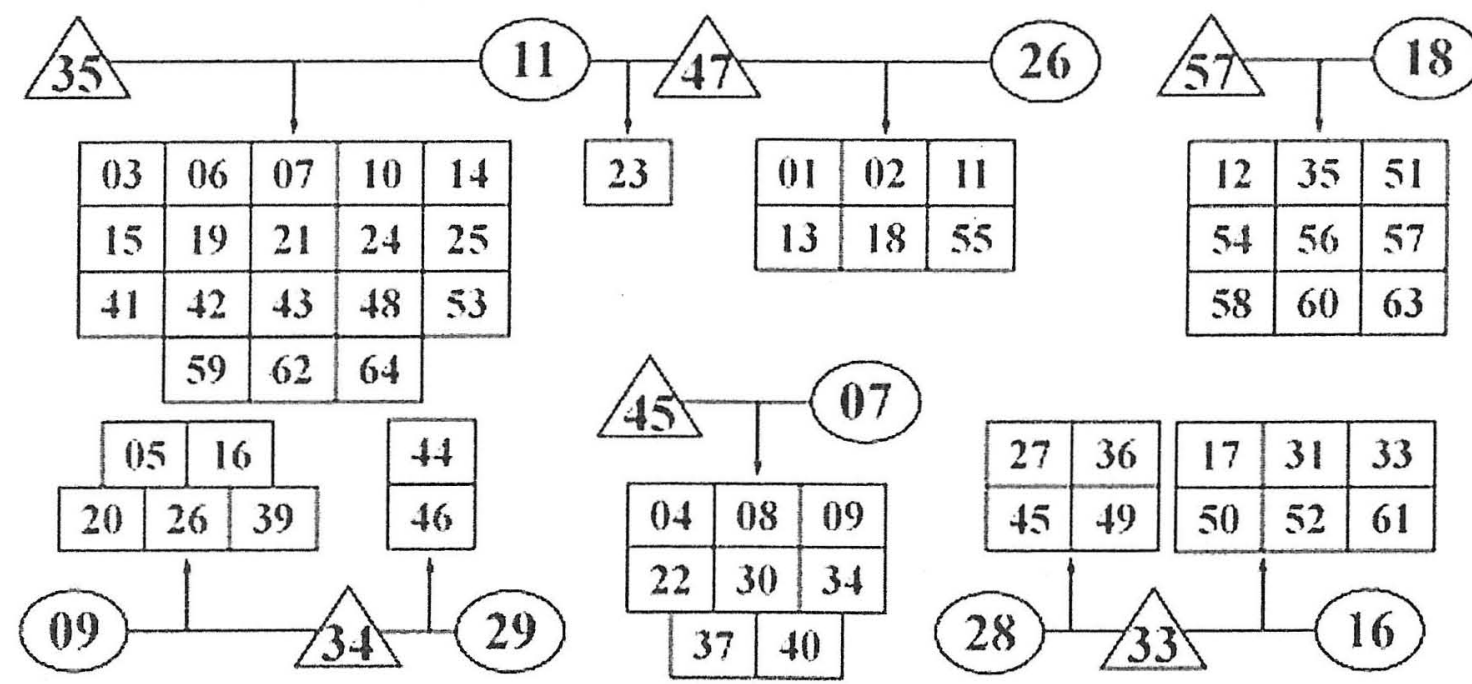

\begin{tabular}{|l|l|l|l|l|}
\hline 27 & 36 \\
\hline 45 & 49 & 31 & 33 \\
\hline 50 & 52 & 61 \\
\hline
\end{tabular} \mid \begin{tabular}{l}
$\mid 33$ \\
\hline
\end{tabular}

(b)
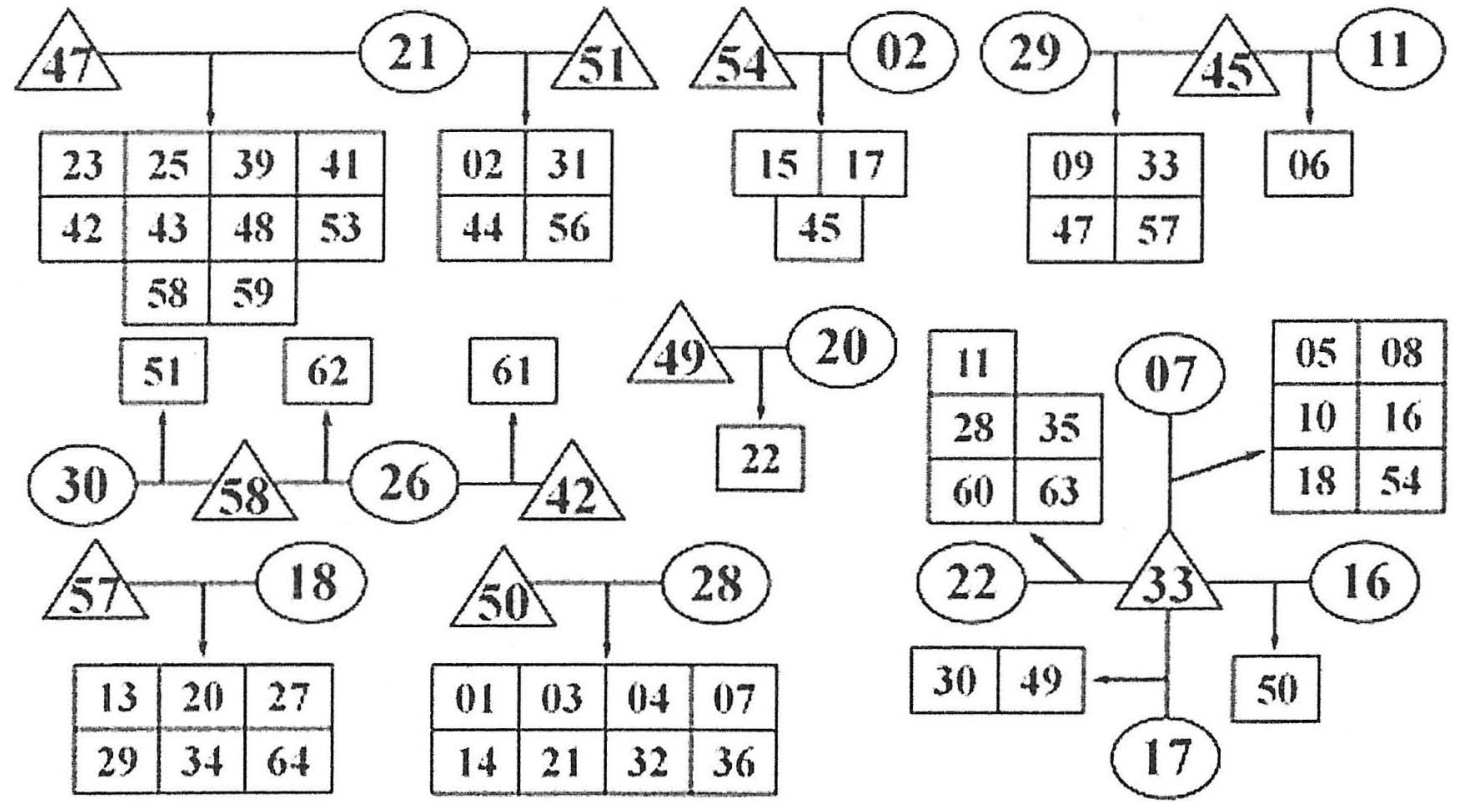

(c)

\begin{tabular}{|c|c|c|c|c|c|c|c|c|c|c|c|}
\hline 02 & 07 & 10 & 12 & 13 & 01 & 03 & 04 & 05 & 06 & 09 & 11 \\
\hline 14 & 15 & 16 & 17 & 19 & 08 & 18 & 20 & 21 & 22 & 23 & 24 \\
\hline 25 & 26 & 27 & 28 & 29 & 31 & 33 & 36 & 37 & 32 & 35 & 39 \\
\hline 30 & 34 & 45 & 47 & 48 & 38 & 40 & 42 & 43 & 41 & 50 & 55 \\
\hline 49 & 52 & 53 & 54 & 58 & 44 & 46 & 51 & 64 & 56 & 57 & 59 \\
\hline 61 & 63 & & & & & & & & 60 & 62 & \\
\hline
\end{tabular}

Fig. 1 Parentage assignments using PAPA software based on genetic data using five microsatellite loci. (a) early phase, (b) middle phase, (c) last phase. Sire $(\triangle)$, dam $(\bigcirc)$, progeny $(\square)$. 
Table 2 Number of alleles $\left(N_{a}\right)$, observed heterozygosity $\left(H_{O}\right)$ and expected heterozygosity $\left(H_{E}\right)$ at five microsatellite loci of brown sole

\begin{tabular}{|c|c|c|c|c|c|c|}
\hline & Phz2 & Phz6 & Phz7 & Phz12 & Phz14 & Mean \\
\hline \multicolumn{7}{|c|}{ Broodstock parent (35 females, 26 males) } \\
\hline$N_{a}$ & 17 & 17 & 27 & 38 & 10 & 21.8 \\
\hline$H_{0}$ & 0.770 & 0.689 & 0.918 & 0.967 & 0.721 & 0.813 \\
\hline$H_{E}$ & 0.873 & 0.763 & 0.886 & 0.971 & 0.679 & 0.834 \\
\hline$H_{O} / H_{E}$ & 0.882 & 0.902 & 1.037 & 0.995 & 1.062 & 0.976 \\
\hline \multicolumn{7}{|c|}{ Early phase progeny } \\
\hline$N_{a}$ & 11 & 6 & 14 & 20 & 7 & 11.6 \\
\hline$H_{O}$ & 0.828 & 0.609 & 0.859 & 0.953 & 0.641 & 0.778 \\
\hline$H_{E}$ & 0.807 & 0.727 & 0.866 & 0.939 & 0.639 & 0.796 \\
\hline$H_{O} / H_{E}$ & 1.027 & 0.838 & 0.992 & 1.015 & 1.003 & 0.975 \\
\hline \multicolumn{7}{|c|}{ Middle phase progeny } \\
\hline$N_{a}$ & 13 & 11 & 16 & 26 & 6 & 14.4 \\
\hline Ho & 0.953 & 0.672 & 0.922 & 0.875 & 0.813 & 0.847 \\
\hline$H_{E}$ & 0.898 & 0.695 & 0.908 & 0.943 & 0.723 & 0.833 \\
\hline$H_{O} / H_{E}$ & 1.062 & 0.966 & 1.016 & 0.928 & 1.124 & 1.019 \\
\hline \multicolumn{7}{|c|}{ Late phase progeny } \\
\hline$N_{a}$ & 9 & 4 & 6 & 8 & 5 & 6.4 \\
\hline$H_{O}$ & 1.000 & 0.391 & 0.641 & 1.000 & 0.750 & 0.756 \\
\hline$H_{E}$ & 0.876 & 0.341 & 0.685 & 0.845 & 0.660 & 0.681 \\
\hline$H_{O} / H_{E}$ & 1.142 & 1.146 & 0.935 & 1.184 & 1.137 & 1.109 \\
\hline
\end{tabular}

Table 3 Genetic parameters for EP, MP, LP and overall group

\begin{tabular}{lcrrrrrrrrrr}
\hline Phase & $N$ & $N_{c}$ & \multicolumn{1}{c}{$\bar{K}_{f}$} & $\bar{K}_{m}$ & $\delta^{2}{ }_{k f}$ & $\delta^{2}{ }_{K m}$ & $N_{e f}$ & $N_{e m}$ & $N_{e}$ & $N_{e} / N$ & $N_{e} / N_{c}$ \\
\hline EP & 61 & 14 & 7.38 & 9.83 & 26.84 & 17.37 & 5.79 & 5.47 & 11.25 & 0.18 & 0.80 \\
MP & 61 & 23 & 4.15 & 5.40 & 14.14 & 17.82 & 8.08 & 6.88 & 14.87 & 0.24 & 0.65 \\
LP & 61 & 5 & 21.33 & 32 & 26.33 & 450 & 2.92 & 1.40 & 3.78 & 0.06 & 0.76 \\
Overall & 61 & 29 & 10.41 & 14.75 & 59.38 & 253.15 & 11.64 & 5.69 & 15.30 & 0.25 & 0.53 \\
\hline
\end{tabular}

$N$, number of broodstock; $N_{c}$, contributed number of parents; $\bar{K}_{f}, \bar{K}_{m}$, averaged progeny count of female and male parents, respectively; $\delta^{2}{ }_{k f}, \delta^{2} \mathrm{Km}$, variance of female and male contributions, respectively, $N_{e f}, N_{e m}$, effective number of females and males, respectively, $N_{e}$, effective population size.

\section{DISCUSSION}

Ortega-Villaizan Romo et al. $^{28}$ reported $85 \%$ assignment to 42 parental fishes ( 24 females and 18 males) for hatchery offspring with three microsatellite loci in spotted halibut. Hara and Sekino ${ }^{9}$ succeeded in $86 \%$ assignment to 72 possible parental pairs (12 females and six males) using only four microsatellite loci in Japanese flounder; however, the confirmed participating parents in the production of the hatchery population were six females and three males. The success rate of parentage assignment is probably affected by the polymorphism of markers and the number of possible parental pairs. In the present study, from 84.4 to $100 \%$ of communal larvae were successfully assigned to a specific parental pair using five microsatellite loci. When compared with the abovementioned studies, ${ }^{9,28}$ the rates of assigned parental fishes (dams and sires) were not low despite the more possible combination of parental pairs (35 females and 26 males) and more contribution of parental pairs (eight dams and six sires, 13 dams and ten sires, and three dams and two sires in EP, MP, and LP, respectively) in the resultant hatchery population. In this study, a brown sole (45M) was found to contribute to mating throughout the spawning time, and seven dams and four sires predominately participated in spawning over two spawning periods. Spawning in brown sole was not finished after one mating but continued throughout the period.

Although $H_{E}$ was not significantly different, $H_{E}$ was lowest in the LP group. $N_{a}$ was also lowest in the LP group. Similar reduction in genetic diversity as inferred by microsatellite DNA markers in hatchery populations has been reported in previous works by other authors. ${ }^{6,9,13,14}$ Such a decrease might be explained by the limited number of broodstock. It is also suggested that the 
contribution of parental fish affects the genetic diversity of progeny according to the spawning time; however, parental fish contributing to LP group progeny were not spawners in EP and MP. MP group progeny were produced by a relatively large number of parental fish, but progeny of the EP and LP groups are also important to maintain the genetic variability of the hatchery, because dams (24F, 31F, and 61F) in the LP group did not contribute to other progeny groups.

The effective number of contributing parents $\left(N_{e}\right)$ was $11.25,14.87$, and 3.78 in EP, MP, and LP groups, respectively, and was much smaller than the number of parental fish $(N=61)$ in a spawning tank $\left(N_{e} / N=0.06-0.24\right)$. However, the $N_{e} / N_{c}$ ratio was $0.65-0.80$ in three groups and 0.53 overall. The estimation of $N_{e}$ and $N_{c}$ in the hatchery population is important for considering management to maintain genetic integrity of the natural resource.

Most progeny ( $70 \%$ in EP, $56 \%$ in MP, and $90 \%$ in LP) died during stages from hatching to 3-monthold juveniles and many larvae were also considered to die in the early developmental stages before hatching. Therefore, most of the minority families died before sampling. In the near future, genetic studies on hatchery populations of the brown sole, parental assignment, and pedigree evaluation should be carried out in early developmental stages before hatching.

Microsatellite DNA markers are good molecular tools not only for parentage assignment but also for monitoring genetic variability in hatchery populations. Population genetic studies using polymorphic DNA markers are necessary for the management of commercially important fish species, in order to avoid the reduction of genetic diversity when such a species is utilized for ocean ranching by releasing seeds into wild populations. Parentage assignment will provide information that the genetic diversity may be decreased in the hatchery population when compared with broodstock or the wild population. Therefore, parentage assignment using microsatellite DNA markers is thought to be a basic approach for the genetic management of artificially produced hatchery populations for stocking fish species.

\section{ACKNOWLEDGMENTS}

This work was supported in part by the 21st Century COE program 'Marine Bio-Manipulation Frontier for Food Production' at Hokkaido University from the Ministry of Education, Culture, Sports, Science and Technology (MEXT), Japan, and the Hokusui Foundation, Japan.

\section{REFERENCES}

1. Liu ZJ, Cordes JF. DNA marker technologies and their applications in aquaculture genetics. Aquaculture 2004; 238 : 1-37.

2. Dunham RA. Biochemical and molecular markers: microsatellites. In: Dunham RA (ed.). Aquaculture and Fisheries Biotechnology: Genetic Approaches. CABI Publishing, London. 2004; 97-99.

3. O'Connell M, Wright JM. Microsatellite DNA in fishes. Rev. Fish. Biol. Fish. 1997; 7: 331-363.

4. Wenburg JK, Bentzen P, Foote CJ. Microsatellite analysis of genetic population structure in an endangered salmonid: the coastal cutthroat trout (Oncorhynchus clarki clarki). Mol. Ecol. 1998; 7: 733-749.

5. Hoarau G, Piquet AM-T, van der Veer HW, Fijnsdorp AD, Stam WT, Olsen JL. Population structure of plaice (Pleuronectes platessa L.) in northern Europe: a comparison of resolving power between microsatellites and mitochondrial DNA data. J. Sea Res. 2004; 51: 183-190.

6. Lundrigan TA, Reist JD, Ferguson MM. Microsatellite genetic variation within and among Arctic charr (Salvelinus alpinus) from aquaculture and natural population in North America. Aquaculture 2005; 244: 63-75.

7. Estoup A, Gharbi K, SanCristobal M, Chevalet C, Haffray P, Guyomard R. Parentage assignment using microsatellites in turbot (Scophthalmus maximus) and rainbow trout (Oncorhynchus mykiss) hatchery populations. Can. J. Fish. Aquat. Sci. 1998; 55: 715-725.

8. Selvamani MJP, Degnan SM, Degnan BM. Microsatellite genotyping of individual abalone larvae: parentage assignment in aquaculture. Mar. Biotechnol. 2001; 3: 478-485.

9. Hara M, Sekino M. Efficient detection of parentage in cultured Japanese flounder Paralichthys olivaceus using microsatellite DNA marker. Aquaculture 2003; 217: 107114.

10. Castro J, Bouza C, Presa P, Pino-Querido A, Riaza A, Ferreiro I, Sánchez L, Martínez P. Potential sources of error in parentage assessment of turbot (Scophthalmus maximus) using microsatellite loci. Aquaculture 2004; 242: 119-135.

11. Jerry DR, Preston NP, Crocos PJ, Keys S, Meadows JRS, Li Y. Parentage determination of Kuruma shrimp Penaeus (Marsupenaeus) japonicus using microsatellite markers (Bate). Aquaculture 2004; 235: 237-247.

12. Sekino M, Saitoh K, Yamada T, Hara M, Yamashita Y Genetic tagging of released Japanese flounder (Paralichthys olivaceus) based on polymorphic DNA markers. Aquaculture 2005; 244: 49-61.

13. Perez-Enriquez R, Takagi M, Taniguchi N. Genetic variability and pedigree tracing of a hatchery-reared stock of red sea bream (Pagrus major) used for stock enhancement, based on microsatellite DNA markers. Aquaculture 1999; 173: 413-423.

14. Jackson TR, Martin-Robichaud DJ, Reith ME. Application of DNA markers to the management of Atlantic halibut (Hippoglossus hippoglossus) broodstock. Aquaculture 2003; 220: 245-259.

15. Jeong D-S, Umino T, Kuroda $K$, Hayashi M, Nakagawa $H$, Kang J-C, Morishima K, Arai K. Genetic divergence and population structure of black sea bream Acanthopagrus schlegeli inferred from microsatellite analysis. Fish. Sci. 2003; 69: 896-902. 
16. Borrell YJ, Alvarez J, Vazquez E, Pato CF, Tapia CM, Sanchez JA, Blanco G. Applying microsatellites to the management of farmed turbot stocks (Scophthalmus maximus L.) in hatcheries. Aquaculture 2004; 241: 133-150.

17. Sekino M, Sugaya T, Hara M, Taniguchi N. Relatedness inferred from microsatellite genotypes as a tool for broodstock management of Japanese flounder Paralichthys olivaceus. Aquaculture 2004; 233: 163-172.

18. Ortega-Villaizan Romo M, Suzuki S, Nakajima M, Taniguchi N. Genetic evaluation of interindividual relatedness for broodstock management of the rare species barfin flounder Verasper moseri using microsatellite DNA markers. Fish. Sci. 2006; 72: 33-39.

19. Satoh N, Fujioka T, Shimizu Y. Ingestion of live food by the larvae of brown sole Pleuronectes herzensteini at different temperatures in the Hokkaido region. Sci. Rep. Hokkaido Fish. Exp. Stn. 2003; 64: 113-120.

20. Satoh N, Sugimoto T. Effects of feeding intervals on the growth of the juveniles of brown sole Pleuronectes herzensteini. Sci. Rep. Hokkaido Fish. Exp. Stn. 2004; 66: 1-5.

21. Kim SG, Morishima K, Arai K. Isolation and Characterization of polymorphic microsatellite DNA markers in the brown sole, Pleuronectes herzensteini. Mol. Ecol. Notes 2007; 7: 79-81.
22. Schuelke M. An economic method for the fluorescent labeling of PCR fragments. Nat. Biotechnol. 2000; 18: 233-234.

23. Lorenz E, Frees KL, Schwartz DA. M13-tailed primers improve the readability and usability of microsatellite analyses performed with two different allele-sizing methods. Biotechniques 2001; 31: 24-27.

24. Duchesne P, Godbout MH, Bernatchez L. PAPA (package for the analysis of parental allocation): a computer program for simulated and real parental allocation. Mol. Ecol. Notes 2002; 2: 191-193.

25. SanCristobal M, Chevalet C. Error tolerant parent identification from a finite set of individuals. Genet. Res. 1997; 70: 53-62.

26. Raymond M, Rousset F. GENEPOP (version 1.2.): population genetics software for exact tests and ecumenicism. J. Hered. 1995; 86: 248-249.

27. Lande R, Barrowclough GF. Effective population size, genetic variation, and their use in population management. In: Soule ME (ed.). Viable Populations for Conservation. Cambridge University Press, Cambridge, UK. 1987; 87-123.

28. Ortega-Villaizan Romo M, Aritaki M, Taniguchi N. Pedigree analysis of recaptured fish in the stock enhancement program of spotted halibut Verasper variegates. Fish. Sci. 2006; 72: 48-52. 